\title{
Correlation Between Inferior Vena Cava Collapsibility Index And Central Venous Pressure To Assess Volume Status Of Critical Patients In Intensive Care Unit In RSUP H. Adam Malik Medan
}

\author{
M. Aldi Rivai Ginting*, Akhyar Hamonangan Nasution**, Soejat Harto** \\ * Resident of Anesthesiology and Intensive Care, Sumatera Utara University Medical Faculty, RSUP H. Adam Malik Medan \\ **Department of Anesthesiology and Intensive Care, Sumatera Utara University Medical Faculty, RSUP H. Adam Malik Medan
}

DOI: 10.29322/IJSRP.11.08.2021.p11676

http://dx.doi.org/10.29322/IJSRP.11.08.2021.p11676

\begin{abstract}
Introduction: Assessment of intravascular volume are essential in improving the patient's condition during critical care, but no single standard examination is ideal. ${ }^{2}$ Sonographic examination is emerging as a potential non-invasive diagnostic tool for assessing intravascular fluid status by measuring IVC diameter. ${ }^{3}$

Objective: To determine correlation between Central Venous Pressure and Inferior Vena Cava Collapsibility Index to assess volume status of critically ill patients in ICU care.

Methods: This is an observational analytic study, with cross sectional method which performed at Intensive Care Unit (ICU) RSUP H. Adam Malik Medan in July-September 2020. Samples were patients aged 18-65 years, with a BMI of 18-30, hospitalized in ICU with central venous catheter. Exclusion criteria were patients with heart defects and pregnant women. The study conducted by examining value of central venous pressure in patients who were admitted to the ICU, then assessing inferior vena cava collapsibility index using Doppler ultrasound. Then, an assessment correlation inferior vena cava collapsibility index and central vena pressure was assessed using the Pearson Correlation test or independent T-test.
\end{abstract}

Results: This study was followed by 31 subjects who met the inclusion criteria. Based on characteristics of sample, sample mean age was $43.45 \pm 16.7$ years with $p=0.069$ and number of female samples was 17 samples $(54.8 \%)$. There was a correlation between IVC CI and CVP with $r=-0.937$ and $p=0.001$, which means there is a strong negative correlation between it and statistically significant. In addition, in correlation between IVC CI and CVP values on use of mechanical ventilation, there was no statistically significant difference in IVC CI values in mechanically ventilated sample with sample not using mechanical ventilation $(\mathrm{p}=0.250)$.

Conclusion: There is a strong negative correlation between inferior vena cava collapsibility index (IVC CI) and central venous pressure (CVP) in assessment of volume status patients hospitalized in ICU.

Keywords: Central Venous Pressure, Inferior Vena Cava Collapsibility Index, Volume status

\section{Introduction}

Early determination of hydration status in critically ill patients, such as adequacy of fluids, is very important in critical care management. There are various methods of assessment, but none of them is the gold standard. Although Central Venous Pressure (CVP) has proven to be unreliable, it is still used worldwide. ${ }^{1}$ Assessment of intravascular volume are essential in improving

This publication is licensed under Creative Commons Attribution CC BY.

http://dx.doi.org/10.29322/IJSRP.11.08.2021.p11676 the patient's condition during critical care, but no single standard examination is ideal. ${ }^{2}$

Sonographic examination is emerging as a potential non-invasive diagnostic tool for assessing intravascular fluid status by measuring IVC diameter. ${ }^{3}$ Both CVP and IVC diameter measurement have similarities in that are methods that view central vein even though measured parameters are different. Several studies have found an association between CVP and variations in IVC diameter. The purpose of this study to 
determine correlation between Central Venous Pressure and Inferior Vena Cava Collapsibility Index to assess volume status of critically ill patients in ICU care.

\section{Methods}

This is an observational analytic study, with cross sectional method performed at Intensive Care Unit (ICU) RSUP H. Adam Malik Medan in July-September 2020. Samples are patients 1865 years old, with a BMI of 18-30, hospitalized in ICU with central venous catheter. patients with heart defects, pregnant women, and administered vasopressor or inotropic agents are excluded. This research was conducted after obtaining approval from Health Research Ethics Committee Universitas Sumatera Utara Medical Faculty and H. Adam Malik General Hospital.

The study are performed by examining central venous pressure value in patients who were admitted to ICU, then assessing inferior vena cava collapsibility index using Doppler ultrasound, early after ICU admission (examination performed by researcher and confirmed by ICU supervisor). Basic data collection such as gender, age, admission diagnosis, laboratory results, and urine output monitoring by volunteers. Then, correlation inferior between vena cava collapsibility index and central vena pressure assessed using Pearson Correlation test or independent T-test.

\section{Result}

This study followed by 31 subjects who met inclusion criteria. Based on characteristics of sample, sample mean age are 43.45 \pm 16.7 years with $\mathrm{p}=0.069$ and female samples are 17 samples (54.8\%). Patient under mechanical ventilator are 20 samples $(64,5 \%)$. Mean IVC CI value are $0,47 \pm 0,18(\mathrm{p}=0,051)$, while CVP are 9,5 $\pm 3,92(\mathrm{p}=0,073)$.

There is a correlation between IVC CI and CVP with $\mathrm{r}$ $=-0.937$ and $p=0.001$, which means there is a strong negative correlation between them and statistically significant. In correlation between CVP and IVC CI with volume status, there is a strong positive correlation between CVP and volume status with $\mathrm{r}=0.803(\mathrm{p}=0.001) .{ }^{1}$ In addition, in correlation between IVC CI and CVP values on use of mechanical ventilation, there is no statistically significant difference in IVC CI values in mechanically ventilated sample with sample not using mechanical ventilation $(\mathrm{p}=0.250)$.

\section{Discussion}

Assessment of intravascular volume very important in improving patients condition during critical care, but there is no ideal examination. ${ }^{2}$ In this study, it is known that IVC CI value has a strong negative correlation with CVP value $(r=-0.937, p$ $=0.001)$. Rinaldi, et al. revealed strong association between CVP values and IVC DI regardless type of ventilation of patient. This is based on hypothesis that physiologically This publication is licensed under Creative Commons Attribution CC BY. http://dx.doi.org/10.29322/IJSRP.11.08.2021.p11676 tendency to stretch (distensibility) and tendency to collapse (collapsibility) of blood vessel is influenced by vascular compliance, where compliance is amount of volume change with each change in pressure that occurs. ${ }^{4}$

Thanakitcharu et al, in their study found a significant correlation between CVP and IVC CI $(r=-0.612, p<0.001)$ in critically hospitalized patients. ${ }^{5}$ Meanwhile, in our study there is no association between use of mechanical ventilation and IVC CI value. This also known in study of Airapetian et al., both IVC diameter and IVC CI were inaccurate in predicting fluid adequacy of patients with spontaneous breathing undergoing ICU care. ${ }^{6}$ Because, in patients with spontaneous breathing there is a decrease in intra-thoracic pressure and increase in intraabdominal pressure during inspiration which increases venous return. Thus, IVC diameter can decrease due to a decrease in IVC transmural pressure. ${ }^{7}$ But, Several research reported a good correlation between right atrial pressure and variation in respiratory IVC in patients with spontaneous breathing.

This study has several limitations, first, number of samples obtained is quite small, so wider sample size is needed to confirm the results obtained in this study. Second, not homogeneous samples using mechanical ventilation could influence the assessment of IVC CI and CVP.

\section{Conclusion}

There is a strong negative correlation between inferior vena cava collapsibility index (IVC CI) and central venous pressure (CVP) in assessment of volume status patients hospitalized in ICU. There was no relationship between use of mechanical ventilation with IVC CI and CVP values. ${ }^{1}$

\section{References}

[1] Govender, J. et al. Is there an association between central venous pressure measurement and ultrasound asessment of the inferior vena cava?, African $J$ of Emergency Med,2018. (8);106-109. doi: 10.1016/j.afjem.2018.03.004

[2] Wiryana,M. Sinardja, K. Aryabiantara, W. et al. Central venous pressure with inferior vena cava collapsibility index in patient treated in intensive care unit, Bali J of Anesth, 2017: 1(1);7-9

[3] Ilyas, A. et al. Correlation of IVC Diameter and Collapsibility Index With Central Venous Pressure in the Assessment of Intravascular Volume in Critically Ill Patients, Cureus. 2017; 9(2):e1025 doi: 10.7759/cureus. 1025 .

[4] Rinaldi Tri Frisianto, Sudadi, Djayanti Sari. Kolerasi nilai Central Venous Pressure (CVP) dengan Inferior 
Vena Cava Distensibillity Index (IVC-DI) pada pasien

ICU RSUP Dr. Sardjito, Terapi Intensif Konsultan Anestesiologi.2016

[5] Thanakitcharu, P., Charoenwut, M. and Siriwiwatanakul, N. Inferior vena cava diameter and collapsibility index: A practical non-invasive evaluation of intravascular fluid volume in critically-III patients, Journal of the Medical Association of Thailand, 2013. 96(SUPPL.3), pp. 14-22.

[6] Airapetian, N. Maizel, J. et al. Does inferior vena cava respiratory variability predict fluid responsiveness in spontaneously breathing patients?, Critical Care. 2015.19:400. DOI:10.1186/s13054-015-1100-9

[7] Lloyd Jr TC. Effect of inspiration on inferior vena caval blood flow in dogs. J Appl Physiol. 1983;55(6):17018.

\section{Correspondence}

Muhammad Aldi Rivai, MD. Resident of Anesthesiology and Intensive Care USU Medical Faculty, Haji Adam Malik Central Hospital Medan, North Sumatra, Indonesia. Email : aldi.oneal@yahoo.com, phone : +62 8126460091

\section{Appendix}

Tabel 1. Demographic Characteristic

\begin{tabular}{lcc}
\hline \multicolumn{1}{c}{ Characteristic } & Subject & P-value $^{\mathrm{a}}$ \\
\hline $\begin{array}{l}\text { Ages (year, mean } \pm \text { SD) } \\
\text { Gender }\end{array}$ & $43.45 \pm 16.7$ & 0,069 \\
$\quad$ Male (n, \%) & $14(45,2 \%)$ & 0.001 \\
$\quad$ Female $(\mathrm{n}, \%)$ & $17(54,8 \%)$ & \\
BMI & $24,6 \pm 2,28$ & 0,138 \\
IVC CI & $0,47 \pm 0,18$ & 0.051 \\
CVP & $9,5 \pm 3,92$ & 0,073 \\
Volume Status & & \\
$\quad$ Hipovolume & $8(25,8 \%)$ & 0,001 \\
$\quad$ Euvolume & $13(41,9 \%)$ & \\
$\quad$ Hipervolume & $10(32,3 \%)$ & \\
Ventilator & & \\
$\quad$ Yes & $20(64,5)$ & 0,001 \\
$\quad$ No & $11(35,5)$ & \\
\hline
\end{tabular}




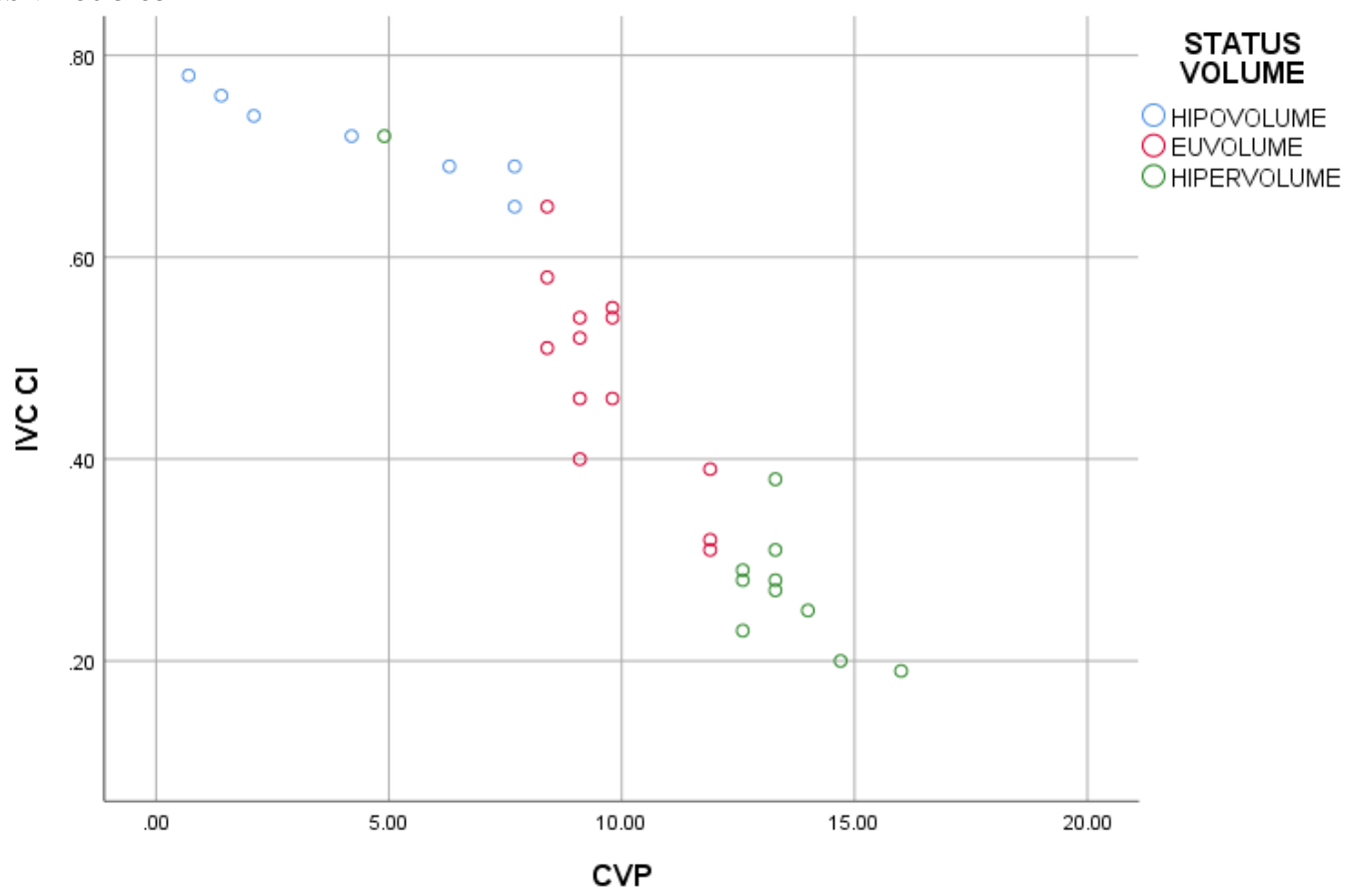

Figure 1. Correlation distribution between IVC CI and CVP with volume status

Table 2. Relationship between IVC CI and CVP values with mechanical ventilation

\begin{tabular}{ccc}
\hline & IVC CI & CVP \\
\hline Mechanical Ventilation & & \\
Ya $(\mathrm{n}=20)$ & $0,44 \pm 0,19$ & $9,7 \pm 4,27$ \\
Tidak (n=11) & $0,52 \pm 0,16$ & $8,9 \pm 3,27$ \\
\hline p-value & $0,250^{\mathrm{c}}$ & $0,227^{\mathrm{c}}$
\end{tabular}

C) T-test independent 